\title{
CAROTID THROMBOSIS IN CHILDHOOD
}

\author{
BY \\ DAVID MYMIN \\ From the Cardiac Department, Royal Liverpool Children's Hospital
}

(RECEIVED FOR PUBLICATION JANUARY 26, 1960)

Although carotid occlusive disease is not uncommon in adults (Fisher, 1954; Samuel, 1956), it is rare in children. Since atherosclerosis is accepted by most authors as the major aetiological agent, this is not surprising. A search of the literature reveals 16 cases of carotid occlusion in persons 10 years of age or less (Duffy, Portnoy, Mauro and Wehrle, 1957; Cabieses and Saldias, 1956; Behrman, 1954; Shapiro, 1952; King and Langworthy, 1941; Litchfield, 1938; Gross, 1945; Martin, Lukeman, Ranson and Geppert, 1954; Goldstein and Burgess, 1958; Pouyanne, Arné, Loiseau and Mouton, 1957; Clark and Linell, 1954; Braudo, 1956; Fairburn, 1957) and a further six below the age of 20 (Pouyanne et al., 1957; Krayenbühl and Weber, 1944; Petit-Dutaillis, Janet, Thiébaut and Guillaumat, 1949; Riechert, 1938; Caldwell, 1936).

Arteriographic, necropsy or operative proof was provided in 17 of these cases; two were diagnosed on the absence of carotid pulsation on the side opposite the hemiplegia and three, associated with trauma, were accepted on convincing circumstantial grounds.

An aetiology was indicated in 13 cases. Litchfield (1938) and Pouyanne et al. (1957) have each reported a case associated with severe throat infection. Gross (1945), in a review of arterial occlusion in infancy, reported two cases in whom emboli from a thrombosed persistent ductus arteriosus were considered to have caused the occlusion. One of these cases also had Fallot's tetralogy with polycythaemia. A paradoxical embolus of necrotic placental tissue was presumed by Clark and Linell (1954) to have caused internal carotid occlusion in an infant with erythroblastosis foetalis. In the case reported by Duffy et al. (1957) thrombosis was probably due to a congenital anomaly of the vessel wall. Martin et al. (1954) have described a case of mucormycosis of the central nervous system in which the thrombosed internal carotid artery was heavily invaded by the organism. Riechert's case (1938) appears to have been related to the presence of a nearby intracranial tumour.
Trauma accounted for five cases (Braudo, 1956; Fairburn, 1957; Caldwell, 1936), direct injury to the soft palate being responsible in each instance.

In all of the proven cases the occlusion was limited to one or other internal carotid artery; one of the others (King and Langworthy, 1941) was thought to have common carotid and right subclavian obstruction on clinical grounds. Bilateral carotid involvement is occasionally encountered (Ochs, Sensenbach and Madison, 1954; Batley, 1955; Silverstein, 1959; Brain, 1957), but has never previously been reported in a child. Common carotid thrombosis constitutes a small fraction of several series of carotid occlusive cases (Silverstein, 1959; Shapiro and Peyton, 1954; Ameli and Ashby, 1949; Gurdjian and Webster, 1953) but no proven case in childhood has yet been reported. The following case of a child with bilateral common carotid thrombosis may thus be worth reporting.

\section{Case Report}

A girl of $2 \frac{1}{4}$ years, was admitted to the Royal Liverpool Children's Hospital for investigation, having recently recovered from an illness diagnosed as left ventricular failure associated with respiratory infection. She was known to have a precordial systolic murmur since the age of 2 months when she presented with a chest infection.

On admission there was no evidence of congestive failure and she was not dyspnoeic. Sinus rhythm was present. The left radial and femoral pulses were diminished and delayed compared with the right radial, and blood pressures were as follows: right brachial $180 / 130 \mathrm{~mm}$. $\mathrm{Hg}$, left brachial $135 / 85 \mathrm{~mm}$. $\mathrm{Hg}$, right femoral $110 / 90 \mathrm{~mm}$. Hg. Both carotid pulses were palpable and of high tension. Scapular collateral arteries could be felt only on the right. The toes were moderately cyanosed but the fingers only slightly. The heart apex beat gave the powerful localized thrust indicative of left ventricular hypertrophy and on auscultation a short systolic bruit of slight to moderate intensity and a short mid-diastolic bruit of moderate intensity were present at the apex. The second heart sound was somewhat accentuated and single. The clinical state was otherwise within normal limits.

The chest radiograph showed a cardio-thoracic ratio 


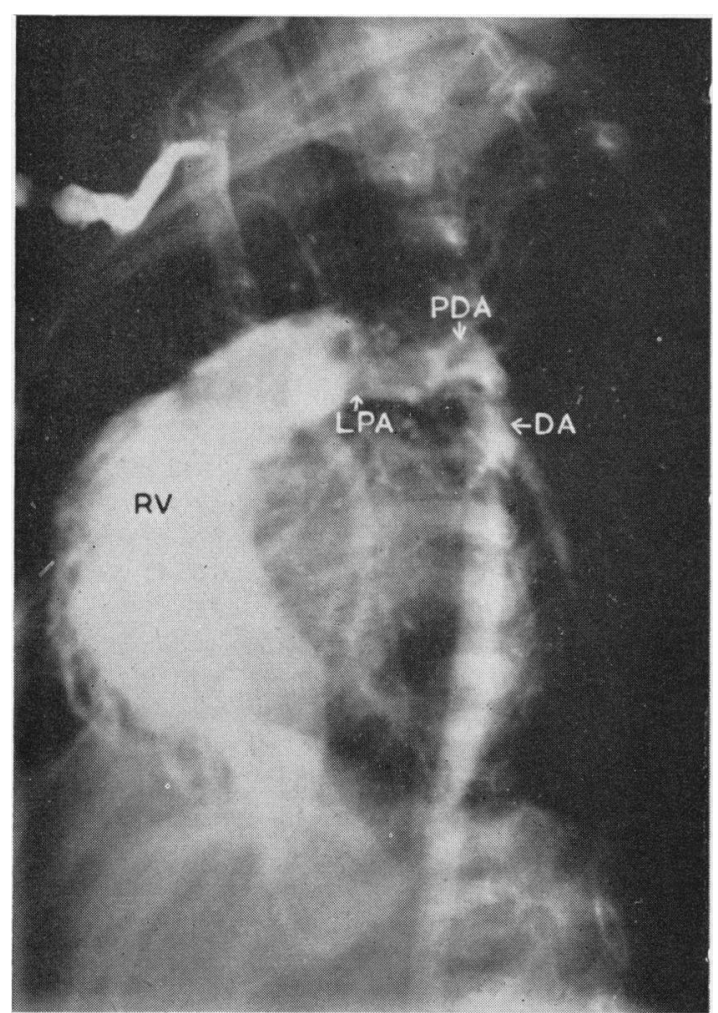

FIG. 1.-Angiocardiogram taken in right posterior oblique position, showing direct passage of dye from left pulmonary artery to descending aorta via ductus arteriosus.

$\mathbf{R V}=$ right ventricle; LPA = left pulmonary artery PDA = patent ductus arteriosus; DA $=$ descending aorta.

of 0.69 and the pulmonary vascular markings were heavy. The electrocardiogram was interpreted as showing biventricular hypertrophy. Her haemoglobin was $95 \%$, white cell count $13,000 /$ c.mm., differential count normal, urine normal and blood urea $25 \mathrm{mg} . / 100$ $\mathrm{ml}$.

Two weeks after admission the patient suddenly developed left hemiparesis; this improved considerably within a few days. She had always been irritable and after this episode her temperament worsened. It was not until two weeks later that the carotid pulses were checked when neither could be felt at all.

Angiocardiography was carried out and this showed direct filling of the descending aorta from the pulmonary artery via a patent ductus arteriosus (Fig. 1). The small proportion of dye which passed through the lungs outlined only the ascending aorta and innominate artery (Fig. 2).

Three days later the right hand and forearm suddenly became cold and blue. The right brachial pulse was unaltered but the radial and ulnar pulses had disappeared. Heparin and 'Priscol' were administered and after several days the colour and temperature of the limb improved. The pulses remained unchanged. A week after the

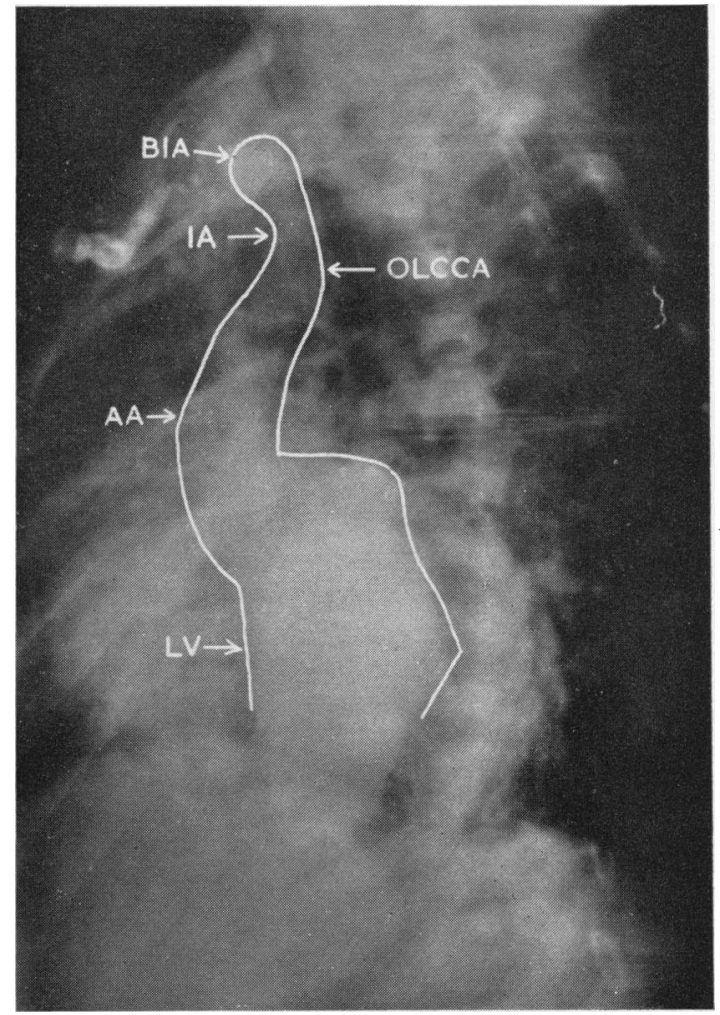

FIG. 2.-Angiocardiogram at a later stage than that shown in Fig. 1. That portion of the dye which has passed through the pulmonary circulation outlines only the left ventricle, the ascending aorta and the innominate artery. Neither carotid vessel has filled. Reference to Fig. 3 assists orientation.

$\mathbf{L V}=$ left ventricle $; \mathbf{A A}=$ ascending aorta $; \mathbf{I A}=$ innominate artery; $\mathbf{B I A}=$ region of bifurcation of innominate artery; OLCCA $=$ region of origin of left common carotid artery.

onset of this episode the patient suddenly became unconscious and died a few hours later.

At autopsy (see Fig. 3) the heart was found to be greatly enlarged. The right ventricle was well developed and its wall up to $5 \mathrm{~mm}$. thick. The left ventricle was markedly hypertrophied, its wall being up to $15 \mathrm{~mm}$. thick and its endocardium white and slightly thickened. The pulmonary artery was normal in appearance but larger in size than the ascending aorta. The ductus was patent and $5 \mathrm{~mm}$. in diameter. There was marked constriction of the aortic arch between the origins of the left common carotid and left subclavian arteries, admitting only a very fine probe. The left atrium was essentially normal apart from some whitening of the endocardium and slight thickening of the mitral valve cusps. The right atrium and the other three valves were normal and there was no abnormality in the anatomy of the pulmonary or systemic venous connections. Atrial and ventricular septa were intact. Adventitial haemorrhages were visible in the following sites: $(a)$ over the root of the left common carotid artery where it was joined by the 


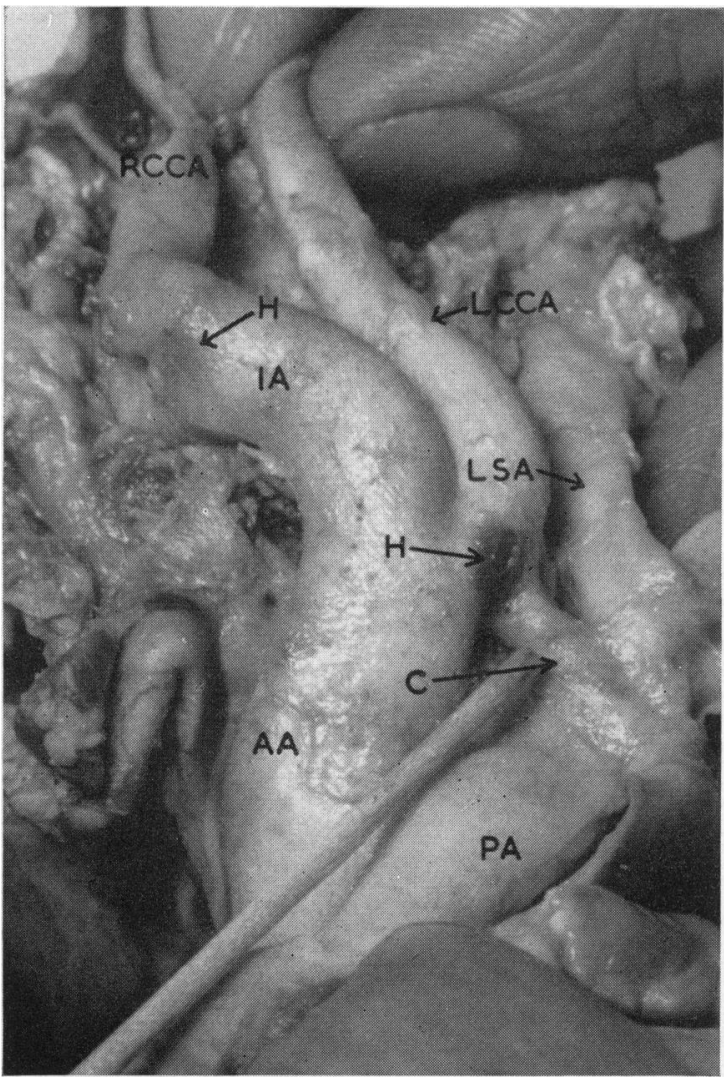

FIG. 3.-Great vessels. The right common carotid artery has been opened at its bifurcation to show the presence of thrombus. A haemorrhage can be seen in the wall of the left common carotid vessel at its junction with the coarctation; another at the bifurcation of the innominate artery is less well seen.

AA $=$ ascending aorta $; \mathbf{I A}=$ innominate artery $\mathbf{R C C A}=$ right common carotid artery; LCCA $=$ left common carotid artery; LSA = left subclavian artery; $\mathbf{C}=$ coarcted aortic arch; PA $=$ pulmonary artery; $\mathbf{H}=$ haemorrhage.

stenosed part of the aortic arch, (b) at the bifurcation of the innominate artery, and (c) at the origin of the first branch of the right subclavian artery. The last was larger than the others and had spread into the adjacent connective tissue. Antemortem thrombus was present $(i)$ in the left common carotid artery, extending from a point $2 \mathrm{~cm}$. distal to its origin to its bifurcation some $3 \mathrm{~cm}$. distally, (ii) in the right common carotid artery, extending from a point $1 \mathrm{~cm}$. distal to its origin to its bifurcation $2.5 \mathrm{~cm}$. distally and (iii) in the right subclavian artery, commencing at the origin of the vertebral artery and extending $4 \mathrm{~cm}$. distally. No origin for emboli was found in the heart or aorta. The lungs showed generalized congestion. In the brain, a small area of softening was present in the right cerebral hemisphere superior to the insula. Thrombus was present in both internal carotids at their junction with the circle of Willis, the right being swollen suggesting antemortem thrombosis. Histology of the left common carotid artery and intracranial portions of both internal carotid arteries showed antemortem thrombus. The vessel walls showed no obvious disease.

\section{Discussion}

The case described was one of pulmonary hypertension with shunt reversal through the patent ductus arteriosus, associated with severe aortic coarctation, and complicated by multiple thromboses in the high tension side of the systemic arterial circulation.

The child appears to have lived for some weeks with occlusion of both common carotid vessels. Her ability to do so with no more than slight hemiparesis and a certain amount of irritability of temperament, was a tribute to her vertebral blood supply; her sudden death can presumably be ascribed to thrombosis of the right subclavian artery with involvement of its vertebral branch. The disturbance affecting the right forearm a few days before death, must have been caused by occlusion of the radial and ulnar arteries, or perhaps the brachial bifurcation. This could have been due to local thrombosis, or embolism from non-occluding right subclavian thrombus.

The cause of the vascular thrombosis is not readily apparent. No source of emboli was found at necropsy. Paradoxical emboli from a silent venous thrombosis would have had to move upstream and negotiate the coarctation in order to pass from the ductus to the carotid and right subclavian arteries: this seems unlikely.

Cross sections of thrombosed artery showed no abnormality of the vessel wall on microscopy. Certainty on this point, however, probably demands longitudinal sections as well, as shown by Moberg and Reinand (1956). They described the case of an infant with aortic coarctation proximal to a patent ductus arteriosus, in which thrombosis of the descending aorta occurred. Differential cyanosis was present as in our case, but could have been either peripheral in type, due to the thrombotic occlusion, or central, due to pulmonary hypertension and shunt reversal. Longitudinal sections of the aorta showed multiple transverse ruptures of microscopic size along its whole length, above and below the coarctation. Thrombosis probably arose at the site of minute intimal ulceration. Also, numerous haemorrhages, situated mainly in the media, were present throughout the aorta. The histology was considered to resemble that usually found in aortic dissecting aneurysms. The common association of the latter with coarctation of the aorta is well known, although rupture distal to the 
stenosis is uncommon, tending usually to involve the ascending aorta.

The presence of adventitial haemorrhages at the proximal ends of the thrombosed vessels suggests that the pathogenesis might have been the same as in Moberg and Reinand's case in which there were haemorrhages in the aortic wall. Longitudinal sections, which might have shown transverse ruptures, were not made in our case.

No other cases of thrombosis of major systemic arteries complicating either coarctation of the aorta or pulmonary hypertension with reversed central shunt, have hitherto been reported.

\section{Summary}

The literature of carotid occlusive disease in childhood is briefly reviewed.

A case of multiple arterial occlusion, including bilateral common carotid thrombosis, in a child with congenital cardiovascular disease is described.

The aetiology of the thrombosis is speculatively discussed.

This case was under the care of Professor J. D. Hay and I would like to thank him for allowing me to report it. I wish also to thank Dr. J. S. Elwood for the autopsy report. They both very kindly provided the photographs.

\section{REFERENCES}

Ameli, D. N. and Ashby, D. W. (1949). Non-traumatic thrombosis of the carotid artery. Lancet, 2, 1078.

Batley, E. (1955). Bilateral internal carotid artery thrombosis. Brit. J. Radio!., 28, 472.

Behrman, S. (1954). Thrombosis of the internal carotid artery. Postgrad. med. $J ., 30,570$.

Brain, R. (1957). Order and disorder in the cerebral circulation. Lancet, 2, 857.
Braudo, M. (1956). Thrombosis of internal carotid artery in childhood after injuries in region of soft palate. Brit. med.J., 1, 665

Cabieses, F. and Saldias, C. (1956). Thrombosis of the internal carotid in a child. Neurology (Minneap.), 6, 677.

Caldwell, J. A. (1936). Postraumatic thrombosis of internal carotid artery: Report of 2 cases. Amer. J. Surg., 32, 522

Clark, R. M. and Linell, E. A. (1954). Case report: Prenatal occlusion of the internal carotid artery. J. Neurol. Neurosurg. Psychiat., 17, 295.

Duffy, P. E., Portnoy, B., Mauro, J. and Wehrle, P. F. (1957). Acute infantile hemiplegia secondary to spontaneous carotid thrombosis. Neurology (Minneap.), 7, 664

Fairburn, B. (1957). Thrombosis of internal carotid artery after soft-palate injury. Brit. med. J., 2, 750 .

Fisher, M. (1954). Occlusion of the carotid arteries. A.M.A. Arch. Neurol. Psychiat., 72, 187.

Goldstein, S. L. and Burgess, J. P. (1958). Spontaneous thrombosis of the internal carotid artery in a seven-year-old child. A.M.A. J. Dis. Child., 95, 538.

Gross, R. E. (1945). Arterial embolism and thrombosis in infancy. Amer. J. Dis. Child., 70, 61 .

Gurdjian, E. S. and Webster, J. E. (1953). Stroke resulting from internal carotid artery thrombosis in the neck. J. Amer. med. Ass., 151, 541.

King, A. B. and Langworthy, O. R. (1941). Neurologic symptoms following extensive occlusion of the common or internal carotid artery. Arch. Neurol. Psychiat. (Chicago), 46, 835.

Krayenbühl, H. and Weber, G. (1944). Die Thrombose der Arteria carotis interna und ihre Beziehung zur Endangiitis obliteraus v. Winiwarter-Buerger. Helv. med. Acta, 11, 289.

Litchfield, H. R. (1938). Carotid artery thrombosis complicating retropharyngeal abscess. Arch. Pediat., 55, 36.

Martin, F. P. Lukeman, J. M., Ranson, R. F. and Geppert, L. J. (1954). Mucormycosis of the central nervous system associated with thrombosis of the internal carotid artery. J. Pediat. 44, 437.

Moberg, A. and Reinand, T. (1956). Aortic thrombosis in infancy; two cases of different etiology. Acta Path. Microbiol. scand. $39,161$.

Ochs, L., Sensenbach, W. and Madison, L. (1954). Primary thrombosis of the internal carotid artery. Amer. J. Med., 17, 374

Petit-Dutaillis, D., Janet, H., Thiébaut, F. and Guillaumat, L. (1949). Effets d'une inversion circulatoire par anastomose carotidojugulaire sur une hémiplégie droite avec aphasie due à une thrombose de la carotide interne d'origine inconnue chez un adolescent de 13 ans. Rev. neurol., 81,997.

Pouyanne, H., Arné, L., Loiseau, P. and Mouton, L. (1957). Considérations sur deux cas de thrombose de la carotide interne

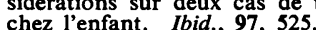

Riechert, T. (1938). Die Arteriographie der Hirngefässe bei einseitigem Verschluss der Carotis interna. Nervenarzt, 11, 290.

Samuel, K. C. (1956). Atherosclerosis and occlusion of the internal carotid artery. J. Path. Bact., 71, 391.

Shapiro, R. (1952). Thrombosis of the internal carotid artery. Radiology, 58, 94.

Shapiro, S. K. and Peyton, W. T. (1954). Spontaneous thrombosis of the carotid arteries. Neurology (Minneap.), 4, 83 .

Silverstein. A. (1959). Occlusive disease of the carotid arteries. Circulation, $20,4$. 